\title{
Malnutrition and associated factors in children: a comparative study between public and private schools in Hohoe Municipality, Ghana
}

\author{
Faith Agbozo ${ }^{1,2}$, Prosper Atito ${ }^{1}$ and Abdulai Abubakari ${ }^{3,2^{*}}$
}

\begin{abstract}
Background: Due to vulnerabilities resulting from disparities in socio-economic status (SES), most nutrition and health interventions are targeted at children in public schools. This study was conducted to investigate the determinants of malnutrition among pupils attending public and private schools in the Hohoe municipality, Ghana.

Methods: School-based cross-sectional survey, which used a multi-stage random sampling technique to select 633 pupils, aged 3-12 years enrolled in 14 public and seven private schools. Data was collected through face-to-face interviews using semi-structured questionnaire. Type of school attended was used as proxy of SES of the pupils. Weight, height and mid upper-arm circumference were measured and used to generate underweight, stunting, thinness and obesity levels using WHO Antroplus and STATA 12.1. Mutually adjusted simple and multinomial logistic regressions were performed to determine associations between explanatory and dependent variables.

Results: Underweight (13\% vs. $2 \%, p=<0.0001)$, stunting ( $12 \%$ vs. $3 \%, p=<0.0001)$ and thinness (8 \% vs. $1.4 \%$, $p<0.0001)$ were higher among pupils attending public schools compared to their private schools counterparts. Public school pupils had increased likelihood for underweight ( $A O R=7.5 ; 95 \% \mathrm{Cl}=2.4-23 ; p=0.001$ ) and an increase risk for thinness ( $R R=4.7 ; 95 \% \mathrm{Cl}=1.5-21.2 ; p=0.028)$ but had decrease risk for overweight $(\mathrm{RR}=0.3 ; 95 \%$ $\mathrm{Cl}=0.1-1 ; p=0.043)$. Overweight (9\%) was higher among private schools pupils compared to public schools (3\%). Underweight (14\% vs. $6 \%$ ), stunting (14\% vs. $4 \%$ ) and thinness ( $8 \%$ vs. $4 \%$ ) were higher among pupils in rural schools compared to urban dwellers. Rural schools children were twice likely to become stunted (AOR $=2.6 ; 95 \%$ $\mathrm{Cl}=1.0-6.4 ; p=0.043)$. However among pupils attending schools in urban areas, the prevalence of overweight was $7 \%$ compare to $1 \%$ in rural areas. Pupils who consumed only two meals per day were more likely to be underweight ( $A O R=6.8 ; 95 \% \mathrm{Cl}=1.4-32.2 ; p=0.016)$, stunted $(\mathrm{AOR}=7.2 ; 95 \% \mathrm{Cl}=1.2-43.7 ; p=0.033)$ and thin $(\mathrm{RR}=9.4 ; 95 \% \mathrm{Cl}=2.0-47.8 ; p=0.007)$ compared to those who had at least three square meals daily.

Conclusion: Both under nutrition and over-nutrition were common among the school pupils but overweight appeared largely driven by high SES and urbanization while under nutrition was associated with low SES and rural residency. Interventions targeting school children should aim at reducing poverty and hunger as these factors remain as underlying causes of malnutrition in childhood.
\end{abstract}

Keyword: School children, Underweight, Stunting, Thinness, Overweight, Socioeconomic status

\footnotetext{
*Correspondence: abubakari.abdulai1@uds.edu.gh; aabubakariabdulai@gmail.

com

${ }^{3}$ Community Nutrition Department, School of Allied Health Sciences,

University for Development Studies, P.Box TL 1883, Tamale, Ghana

${ }^{2}$ Institute of Public Health, University of Heidelberg, Heidelberg, Germany

Full list of author information is available at the end of the article
} 


\section{Background}

Malnutrition among children in developing countries is a major public health concern since it places a heavy burden on already disadvantaged communities [1]. Primary school life is a dynamic period of physical growth as well as of mental development of children and therefore, represents an active growing phase of childhood [2]. Research indicates that health problems due to suboptimal nutritional status in primary school-age children are among the causes of low school enrolment, high absenteeism, early dropout and unsatisfactory classroom performance [3].

Despite the economic growth observed in developing countries, particularly Ghana, malnutrition and more importantly under nutrition is still highly prevalent in some parts of the country [4]. Concomitantly, a growing prevalence of obesity and its related chronic diseases is being observed in these countries [5]. Obesity is already a major concern in developed countries for pre-school children [6] as well as schoolchildren [7].

In developing countries, this rising epidemic along with the tenacity of under nutrition and infections epitomizes the 'Double Burden of Malnutrition' (DBM) [8], which is becoming a great concern for African countries [9]. This is due to changes such as urbanization and the associated changes in lifestyle thus creating obesogenic environment $[10,11]$, which have been shown to contribute immensely to the current increasing trend of malnutrition in the developing countries [12]. This is due to the consumption of energy dense and fatty diet from fast food outlets, reduced active commuting to work, use of energy saving devices and computer games. Undoubtedly, the DBM is a threat at the population, household and even individual level [13], and it is currently observed among schoolchildren [14]. However, in the developing countries, overweight and obesity appear to be more common among the high socioeconomic class [15-17]. Meanwhile, children of low socioeconomic status are vulnerable to under nutrition and poor health outcomes rather than over nutrition, [18]. Findings from Columbia showed that malnutrition had negative impact on school achievement [3].

In private schools where children from high socioeconomic background [19-21] attend the situation of childhood obesity is more prevalent. For example a study conducted in Burkina Faso in 2011 showed that there was high prevalence of overweight among children attending private schools compare to those attending public schools [22]. Similar observations were made in studies conducted in other developing countries such as Guatemala [23] and India [24].

Globally, a quarter of children under-five years are stunted with $15 \%$ underweight, $8 \%$ wasted and $6 \%$ overweight. It is observed that in the low and high- income country groups overweight increase at a similar rate, but at different levels [25]. However, there are higher levels of stunting (37\%), underweight (21\%) and wasting (9\%) [26]. Ghana has made a substantial progress in reducing under nutrition among children less than five years. The Ghana demographic and health survey in 2014 showed that $19 \%$ of children less than five years were stunted, $5 \%$ were wasted and $11 \%$ were underweight [27]. This is a decrease from the $28 \%$ stunting, $9 \%$ wasting and $14 \%$ underweight prevalence recorded in 2008 [28]. However the situation in children of school going age is not known nationwide, as it is not reported in the Ghana Demographic and Health survey. More importantly studies investigating nutritional status of school children particularly between private and public schools in Ghana are limited.

Factors that lead to malnutrition are complex, multidimensional and are often interrelated. Therefore, if the present prevalence of malnutrition in children in developing countries is to be reduced, then it is important that the most important causes of malnutrition should be understood [29]. Besides this, assessing the nutritional status of children is an essential part of monitoring their health status and providing data for accurate planning and implementation of interventions to reduce morbidity and mortality associated with suboptimal nutrition. It is in the light of this that this study was conducted to assess the nutritional status and associated determinants of children enrolled in public and private basic schools in the Hohoe municipality of the Volta region of Ghana.

\section{Method}

Study area

The study was conducted in the Hohoe municipality, one of the 25 administrative districts in the Volta region of Ghana. The municipality is situated in the middle of the region with an estimated population of 167,016 inhabitants comprising $52.1 \%$ females and $47.9 \%$ males living in over 180 rural (47.4 \%) and urban (52.6\%) communities. The population of the municipality is youthful with $35.9 \%$ under age 15 years. The municipality covers a total land area of $1172 \mathrm{~km}^{2}$ and divided into seven zones called sub-municipalities for administrative purposes [30]. There are 91 basic schools within the Hohoe municipality with a total pupil population of 24,798 at kindergarten and primary school levels. Out of this figure, 17,265 pupils are enrolled in 69 public (stateowned) basic schools whereas 7533 pupils are enrolled in 22 private (individual-owned) basic schools.

\section{Design, target population and sampling}

An exploratory school-based cross-sectional design was used. The target population was preschoolers and school 
age children enrolled in public (state-owned) and private (individually-owned) basic schools within the Hohoe municipality. In Ghana, basic schools provide formal education that entails foundation courses starting from kindergarten to the junior high school level. Children in kindergarten are preschoolers while those from primary one to six are school age children with primary one to three termed lower primary and primary four to six termed upper primary. The study population consisted of kindergarten and primary school children.

The sample size was determined using alpha of 1.96 at $95 \%$ confidence interval with a permitted $3 \%$ margin of error considering a $17 \%$ [29] population prevalence of under nutrition. This generated a sample size of 633. A multi-stage sampling method was used in the selection of study schools and participants. There are seven subdistricts in the municipality. To get a representative sample of the municipality, the seven sub-districts were treated as clusters. Two public primary schools were randomly selected from each cluster while seven private schools were selected randomly from the 22 private schools in the Municipality. Within the study schools, eight strata corresponding with the classes were identified. These were kindergarten one and two and primary one to six. Using the class register as the sampling frame, proportionate number of males and females were systematically sampled from each stratum. However, for a school pupil to be eligible to participate on the study, he/she should have enrolled in the school for at least one academic year.

\section{Data collection tools and procedures}

Data was collected by nutrition officers at the second term of the 2014 academic year specifically from January to April. Data collection was done through face-to-face interviews using a semi-structured questionnaire designed to achieve the objectives of the study. One-onone interviews were conducted with participants in upper primary whereas parents and guardians and sometimes teachers of pupils in kindergarten and lower primary were invited to provide responses to the interview questions. Responses elicited included age, class, and occupation of the child's guardian, frequency of fruit and breakfast consumption by the child per week. Anthropometric measurements were taken following WHO standard anthropometry guidelines. Height was measured using 'SECA' stadiometre to the nearest $0.1 \mathrm{~cm}$, weight was measured using digital weighing scale to the nearest $0.1 \mathrm{~kg}$ and mid-upper arm circumference (MUAC) was measured using non-extensible MUAC tape to the nearest $0.1 \mathrm{~mm}$. Measurement errors were reduced by engaging trained nutrition officers employed by the Ghana Health Service to assist with taking anthropometric measurements.

\section{Statistical analysis}

Weight, height and MUAC measurements were converted to weight-for-age Z-scores (WAZ), height-for-age Z-scores (HAZ), body mass index (BMI), BMI-for-age Z-scores (BAZ) and MUAC-for-age $\mathrm{z}$ scores (MAZ) using the WHO Anthroplus software (version 10.4). The resulting indices were used to determine the levels of malnutrition. Underweight was defined as WAZ less than -2 of the mean standard deviation (SD), stunting as HAZ less than -2 SD and thinness also as BAZ less than $-2 \mathrm{SD}$. Overweight and obesity were defined as BAZ greater than +1 SD and +2 SD respectively. However for those who were between the ages of 3-5 years, overweight was defined as BAZ greater than $+2 \mathrm{SD}$ and obesity greater than $+3 \mathrm{SD}$. Weight-for-age is a composite index of weight-for-height and height-for-age and thus does not distinguish between acute malnutrition (wasting) and chronic malnutrition (stunting). Children can be underweight for their age because they are stunted, wasted, or both. Weight-for-age is therefore considered an overall indicator of a population's nutritional health.

Besides this, the type of school attended was used as a proxy of the socio-economic status of the parents or guardians of the school pupils. This was based on the premises that rich parents are more likely to send their children to private schools compare to poor household [19-21].

Data entry and analysis was done using STATA (version 12.1). Both descriptive and inferential statistics were used in analyzing and reporting findings. Differences in characteristics among participant enrolled in the public and private basic schools were determined using Pearson's Chi-square test for categorical variables, which were presented as frequencies and proportions. Student's t-test was used for continuous variables involving two categories and reported as means with standard deviations (SD). The association between the determinants of malnutrition under investigation (independent variables) and the dependent variables (anthropometric indices), that is, underweight and stunting were determined using simple logistic regression. To get the best fit, the regression analysis was mutually adjusted for all the variables included in the model. Multinomial logistic regression model was used to determine the association between BMI-for-age Z-scores (BAZ) and the explanatory variables. This regression was used because the BAZ was classified into three categories; thinness, normal weight and overweight. Differences were significant if $p<0.05$ at $95 \%$ confidence interval.

\section{Results}

The results of the study show that $65.9 \%$ of the pupils attend public schools and $34.1 \%$ attend private schools. 
The majority of the pupils $(81.7 \%)$ were within the age ranges of 6-12 years while $18.3 \%$ were in the age ranges of 3-5 years. A greater proportion of the pupils (94\%) also had breakfast every morning before going to schools as against $6 \%$ who did not have breakfast before going to school. Also, the majority (73.6 \%) consumed at least 3 square meals on daily basis, $24.8 \%$ had four meals per day while $1.6 \%$ had only two meals per day. Moreover $25 \%$ had at least one peace of fruit per day while the remaining $75 \%$ did not.

Besides this, parents/guardians of about $38 \%$ of the pupils engaged in petty trading while $28 \%$ are involved in agriculture mainly crop farming. The rest of the pupil's had their guardians involve in artisanal work (14\%), $13 \%$ were unemployed (13\%) and $7 \%$ were formal sector employees (Table 1).

Overall the prevalence of underweight, stunting, thinness and overweight in the study population was 9.3, 8.5, 5.7 and $4.6 \%$ respectively. Also stunting and thinness were high (11.6 and $7.9 \%$ respectively) among pupils attending public schools as against those attending private schools $(2.8$ and $1.4 \%$ respectively). However, $9 \%$ of pupils attending private schools were overweight as against $3 \%$ of those attending schools in public schools (Table 2). There were statistically significant associations between stunting, underweight and BMI for age z-scores, and the type of school the pupils attended. There were also significant associations between locations of pupils (rural versus urban), guardian's occupation, and number of meals consumed in a day and the type of school attended (Table 2).

There were however not significant associations between the weights, heights and MUAC Z-scores of the pupils and the type of school the pupils attended. However, pupils who attended private schools had higher mean WAZ-scores (0.47) compared to those who attended public schools. Similarly, pupils in private schools had higher mean HAZ-scores (0.48) as against pupils attending public schools (Table 2).

Table 3 illustrates the determinants of underweight and stunting among the study population. About $13 \%$ of the pupils attending public schools were underweight compared to $1.85 \%$ among those who attended private schools. It was observed that pupils attending public schools were about seven folds more likely to be underweight $(\mathrm{AOR}=7.5 ; \mathrm{CI}=2.4-23 ; p=0.001)$ compared to those attending private schools. There was also high proportion of underweight in pupils attending schools in rural areas (13.8 \%) compared to those attending schools in urban areas (5.6\%). The results also show that 15.2, 13.5, 11.1, 10.1 and $4.2 \%$ of the pupils whose guardians were formal sector employees, farmers, unemployed, artisans and petty traders respectively were underweight.
Table 1 Socio-demographic characteristics of study participants enrolled in public and private basic schools

\begin{tabular}{|c|c|c|c|}
\hline Variables & $\begin{array}{l}\text { Public schools } \\
\text { n/N(\%) }\end{array}$ & $\begin{array}{l}\text { Private schools } \\
\mathrm{n} / \mathrm{N}(\%)\end{array}$ & $P$-value \\
\hline \multicolumn{4}{|l|}{ Sex } \\
\hline Male & 206/417 (49.4) & 106/216 (49.1) & \multirow[t]{2}{*}{0.938} \\
\hline Female & 211/417 (50.6) & 110/216 (50.9) & \\
\hline Age (years) & $8.4 \pm 2.6$ & $8.1 \pm 7.5$ & 0.097 \\
\hline \multicolumn{4}{|l|}{ Age groups (years) } \\
\hline $3-5$ & 78/417 (18.7) & $38 / 216(17.6)$ & \multirow[t]{2}{*}{0.732} \\
\hline $6-12$ & 339/417 (81.3) & 178/216 (82.4) & \\
\hline \multicolumn{4}{|l|}{ Class groups } \\
\hline Kindergarten & 112/417 (26.9) & $55 / 216(25.5)$ & \\
\hline Lower primary & 158/417 (37.9) & $84 / 216(38.9)$ & \multirow[t]{2}{*}{0.928} \\
\hline Upper primary & 147/417 (35.3) & $77 / 216(35.7)$ & \\
\hline \multicolumn{4}{|l|}{ Location of school } \\
\hline Rural & 291/417 (69.8) & 0 & \multirow[t]{2}{*}{-} \\
\hline Urban & 126/417 (30.2) & 216/216 (100) & \\
\hline \multicolumn{4}{|l|}{ Guardian Occupation } \\
\hline Formal & 22/417 (5.3) & 24/216 (11.1) & \multirow{5}{*}{0.000} \\
\hline Petty trader & 134/417 (31.1) & 105/216 (48.6) & \\
\hline Unemployed & $52 / 417(12.5)$ & 29/216 (13.4) & \\
\hline Artisan & 47/417 (11.3) & 42/216 (19.4) & \\
\hline Farmer & $162 / 417(38.85)$ & $16 / 216(7.4)$ & \\
\hline \multicolumn{4}{|l|}{ Fruit 3 times per week } \\
\hline Yes & $81 / 417$ (19.4) & 79/216 (36.57) & \multirow[t]{2}{*}{0.000} \\
\hline No & 336/417 (80.6) & 137/216 (63.4) & \\
\hline \multicolumn{4}{|l|}{ Breakfast every morning } \\
\hline Yes & $394 / 417$ (94.5) & 201/216 (93.1) & \multirow[t]{2}{*}{0.473} \\
\hline No & 23/417 (5.5) & $15 / 216(6.9)$ & \\
\hline \multicolumn{4}{|c|}{ Number of meals eaten in a day } \\
\hline At least 2 times daily & 9/10 (90.0) & $1 / 10(10.0)$ & \multirow[t]{3}{*}{0.000} \\
\hline 3 times daily & $347 / 466(74.5)$ & $119 / 466(5.5)$ & \\
\hline 4 times daily & 61/157 (38.9) & $96 / 157(61.2)$ & \\
\hline
\end{tabular}

There was a decrease chance for underweight among pupils whose parents were engaged in petty trading $(\mathrm{AOR}=0.2 ; \mathrm{CI}=0.1-0.6 ; p=0.002)$ compared to those whose parents had formal employment (Table 3 ).

Moreover, it was found that the proportion of underweight among pupils who did not consume fruits regularly $(10.2 \%)$ as well as those who did not take breakfast before going to school (13.2\%) were high compared to those who consumed fruits $(7 \%)$ or took breakfast before going to school (9.1\%). Besides this, $30 \%$ of those who had only two meals per day were underweight as compared to 10.1 and $5.7 \%$ respectively for pupils who had at least three square meals and four meals per day. It was observed that pupils who had two meals per day 
Table 2 Anthropometry of study participants attending public and private schools

\begin{tabular}{llll}
\hline Variables & Public schools $n=417($ Mean \pm SD) or $n / \mathrm{N}(\%)$ & Private schools $n=216($ Mean \pm SD) or $n / N(\%)$ & $P$-value \\
\hline Weight $(\mathrm{kg})$ & $24.9 \pm 7.5$ & $25.8 \pm 7.9$ & $0.1414^{\mathrm{a}}$ \\
Height $(\mathrm{cm})$ & $125.4 \pm 14.4$ & $127.4 \pm 14.2$ & $0.9905^{\mathrm{a}}$ \\
WAZ & $-0.82 \pm 1.0$ & $-0.35 \pm 1.0$ & $<0.0001^{\mathrm{a}}$ \\
HAZ & $-0.58 \pm 1.0$ & $0.10 \pm 1.1$ & $<0.0001^{\mathrm{a}}$ \\
MUAC Z-scores & $-0.7 \pm 1.0$ & $-0.70 \pm 0.8$ & $0.9924^{\mathrm{a}}$ \\
BMI-for-age Z-scores & $-0.53 \pm 1.0$ & $-0.47 \pm 0.84$ & $0.3995^{\mathrm{a}}$ \\
Underweight & $55 / 417(13.2)$ & $4 / 216(1.85)$ & $<0.0001^{\mathrm{b}}$ \\
Stunting & $49 / 417(11.6)$ & $5 / 216(2.8)$ & $<0.0001^{\mathrm{b}}$ \\
Thinness & $33 / 417(7.9)$ & $3 / 216(1.4)$ & $0.001^{\mathrm{b}}$ \\
Overweight & $12 / 417(2.9)$ & $20 / 216(9.3)$ & $0.008^{\times}$
\end{tabular}

${ }^{\mathrm{a}}$ Denotes differences derived from t-test

${ }^{\mathrm{b}}$ Denotes differences derived from Pearson Chi-square

were about 7 folds more likely to become underweight $(\mathrm{AOR}=6.8 ; \mathrm{CI}=1.4-32.2 ; p=0.016)$ as compared to those who had at least three square meals per day (Table 3).

In addition to this, high proportion of stunting was observed in pupils enrolled in public schools (11.6\%) compared to those enrolled in private schools $(2.3 \%)$. However, differences observed in the proportion of stunting between pupils attending public and private schools was not statistical significant. Similarly there was also high proportion of stunting in pupils attending schools in rural areas (14.4\%) compare to those attending schools in urban areas (3.5\%). Pupils attending schools in rural areas were about three folds more likely to become stunted ( $\mathrm{AOR}=2.6 ; \mathrm{CI}=1.0-6.4 ; p=0.043$ ) compared to those attending schools in urban areas. More so, 14.0, 13.0, 11.2, 7.5 and $2.9 \%$ of the pupils whose guardians are farmers, formal sector employees, artisan, unemployed and petty traders respectively were stunted. There was a decrease odds for stunting for pupils whose parents are petty traders $(\mathrm{AOR}=0.2 ; \mathrm{CI}=$ $0.1-1 ; p=0.003)$ compared to those whose parents are employed in the formal sector (Table 3).

Additionally, $20 \%$ of pupils who had only two meals per day were stunted as against 10.3 and $2.6 \%$ respectively of pupils who had at least three square meals and four meals per day. Pupils who had only two square meals per day were about seven times more likely to be stunted ( $\mathrm{AOR}=7.2 ; \mathrm{CI}=1.2-43.7 ; p=0.033$ ) compared to those who had at least three square meals per day. Those who had four meals per day had decrease odds for stunting compared to those who had three meals per day but this was only significant at $90 \%$ confidence interval (Table 3).

Further, there was a high proportion of thinness among pupils attending public schools $(7.9 \%)$ as against $1.4 \%$ of pupils attending private schools. It was observed that the risk of being thin as against normal weight for pupils attending public schools was 5.5 times higher compared to those attending private schools $(R R=5.5$; $\mathrm{CI}=1.5-21.2 ; p=0.013)$ while the risk of being overweight as against normal foe pupils attending public schools was $70 \%$ lower $(\mathrm{RR}=0.3 ; 95 \% \mathrm{CI}=0.1-1 ; p=$ 0.043) compare to those in public schools. Likewise, the proportion of pupils who were thin was high among pupils attending schools in rural areas $(8.3 \%)$ compared to those attending schools in urban areas $(3.5 \%)$. Moreover, $30 \%$ of pupils who had only two meals per day were thin compared to those who had at least three square meals $(5.6 \%)$ and four meals $(4.5 \%)$ per day respectively. The risk of being thin as against normal weight for pupils who had only two meals per day were about nine folds higher $(\mathrm{RR}=9.4 ; \mathrm{CI}=2.0-47.8$; $p=0.007)$ compared to those who had at least three meals a day. Similarly, the risk of being thinness as against normal for upper primary (class 4-6) was about 2 times higher $(\mathrm{RR}=2.3 ; \mathrm{CI}=1.0-5.2 ; p=0.045)$ compared to those in lower primary (Table 4).

Conversely, the proportion of overweight among pupils in the private schools was high $(9 \%)$ as against pupils who attend public schools (3\%). It was also observed that the proportion of pupils who were overweight was high in pupils attending schools in urban areas $(7 \%)$ compared to those attending schools in rural areas $(1 \%)$ (Table 4$)$.

Besides this, about $11 \%$ (Table 2) of the variations in underweight, $13 \%$ (Table 3 ) of the variations in stunting and about $15 \%$ (Table 4 ) of the variations in BMI-forage were explained by the determinants investigated in the present study.

\section{Discussion}

The study investigated determinants of malnutrition among public and private school pupils recruited from 
Table 3 Simple logistic regression models showing the determinants of underweight and stunting among the study population

\begin{tabular}{|c|c|c|c|c|c|c|}
\hline \multirow{2}{*}{$\begin{array}{l}\text { Exploratory } \\
\text { variables }\end{array}$} & \multicolumn{3}{|l|}{ Underweight } & \multicolumn{3}{|l|}{ Stunting } \\
\hline & $n / N(\%)$ & AOR $(95 \% \mathrm{Cl})$ & $P$-value & $n / N(\%)$ & AOR (95 \% Cl) & $P$-value \\
\hline \multicolumn{7}{|l|}{ School type } \\
\hline Public & $55 / 417(13.2)$ & $7.5(2.4-23)$ & 0.001 & 49/417(11.6) & $2.7(0.8-8.8)$ & 0.108 \\
\hline Private & $4 / 216(1.85)$ & Reference & & $5 / 215(2.3)$ & Reference & \\
\hline \multicolumn{7}{|l|}{ Sex } \\
\hline Male & 28/312(9.0) & Reference & & 26/321(8.1) & Reference & \\
\hline Female & $31 / 321(9.7)$ & $0.9(0.5-1.5)$ & 0.611 & 28/312(9.0) & $1.1(0.6-1.9)$ & 0.855 \\
\hline \multicolumn{7}{|l|}{ Location of school } \\
\hline Urban & 19/342(5.6) & Reference & & $12 / 341(3.5)$ & Reference & \\
\hline Rural & 40/291(13.8) & $1.2(0.6-2.5)$ & 0.663 & 42/291(14.4) & $2.6(1.0-6.4)$ & 0.043 \\
\hline \multicolumn{7}{|c|}{ Age of pupils (years) } \\
\hline $3-5$ & 10/116(8.6) & Reference & & 9/115(7.8) & Reference & \\
\hline $6-12$ & 49/517(9.5) & $1.1(0.4-3.5)$ & 0.828 & 45/517(8.7) & $0.7(0.3-4.7)$ & 0.637 \\
\hline \multicolumn{7}{|c|}{ Guardian occupation } \\
\hline Formal & $7 / 46(15.2)$ & Reference & & $6 / 46(13.0)$ & Reference & \\
\hline Petty trader & 10/239(4.2) & $0.2(0.1-0.6)$ & 0.002 & $7 / 239(2.9)$ & $0.2(0.1-1)$ & 0.003 \\
\hline Unemployed & 9/81(11.1) & $0.5(0.2-1.6)$ & 0.268 & $6 / 80(7.5)$ & $0.5(0.1-1.7)$ & 0.270 \\
\hline Artisan & 9/89(10.1) & $0.5(0.2-1.6)$ & 0.256 & 10/89(11.2) & $0.8(0.2-2.3)$ & 0.627 \\
\hline Farmer & 24/178(13.5) & $0.4(0.2-1.2)$ & 0.099 & 25/178(14.0) & $0.5(0.2-1.4)$ & 0.173 \\
\hline \multicolumn{7}{|c|}{ Fruit consumption $\geq 3$ times weekly } \\
\hline Yes & $11 / 160(6.9)$ & Reference & & $8 / 159(5.0)$ & Reference & \\
\hline No & $48 / 473(10.2)$ & $1.0(0.5-2.2)$ & 0.932 & $46 / 473(9.7)$ & $1.4(0.6-3.4)$ & 0.394 \\
\hline \multicolumn{7}{|c|}{ Eats breakfast every morning before school } \\
\hline Yes & $54 / 595(9.1)$ & Reference & & $52 / 594(8.8)$ & Reference & \\
\hline No & $5 / 38(13.2)$ & $1.8(0.6-5.1)$ & 0.298 & 2/38(5.3) & $0.7(0.1-3.2)$ & 0.596 \\
\hline \multicolumn{7}{|c|}{ Frequency of meals in a day } \\
\hline Twice daily & $3 / 10(30.0)$ & $6.8(1.4-32.2)$ & 0.016 & $2 / 10(20.0)$ & $7.2(1.2-43.7)$ & 0.033 \\
\hline 3 times daily & $47 / 466(10.1)$ & Reference & & 48/465(10.3) & Reference & \\
\hline 4 times daily & 9/157(5.7) & $1.2(0.5-2.7)$ & 0.743 & 4/157(2.6) & $0.4(0.1-1.1)$ & 0.084 \\
\hline \multicolumn{7}{|l|}{ Class group } \\
\hline Kindergarten & 15/167(9.0) & $1.0(0.5-2.3)$ & 0.707 & $12 / 166(7.2)$ & $0.5(0.2-21.7)$ & 0.282 \\
\hline Lower primary & $26 / 242(10.7)$ & Reference & & 24/242(9.9) & Reference & \\
\hline Upper primary & 18/224(8.0) & $0.7(0.4-1.4)$ & 0.307 & 18/224(8.0) & $1.2(0.6-2.5)$ & 0.596 \\
\hline \multicolumn{4}{|c|}{ Prob $>$ chi $^{2}=0.0000$, Pseudo $R^{2}=0.1143$} & \multicolumn{3}{|c|}{ Prob $>c h i^{2}=0.0000$, Pseudo $R^{2}=0.1340$} \\
\hline
\end{tabular}

kindergartens and primary schools in the Hohoe Municipality. The type of school attended was used as a proxy of the socio-economic status of the parents or guardians. This was based on the premises that rich parents are more likely to send their children to private schools compare to poor households [19-21]. The use of the type school attended (public or private) by pupils in this study as a proxy for the socio-economic background of the parents or guardian makes it unique and different.

The key findings of this study included the following. Firstly, there was high proportion of underweight, stunting and thinness among pupils attending public schools compared to their private school counterparts. Pupils attending public schools were also several folds more likely to become underweight and thin compared to those who attend private schools. On the contrary, there was high proportion of overweight among pupils attending private schools compared to public schools. Pupils attending public schools had lower risk for overweight. This implies that the type of school attended (public vs. private) could be associated with pupils' nutritional status. 
Table 4 Multinomial logistic regression model showing the determinants of thinness and overweight/obesity among school pupils

\begin{tabular}{|c|c|c|c|c|c|c|}
\hline \multirow{2}{*}{$\begin{array}{l}\text { Exploratory } \\
\text { variables }\end{array}$} & \multicolumn{3}{|l|}{ Thinness } & \multicolumn{3}{|c|}{ Overweight/obesity } \\
\hline & $\mathrm{n} / \mathrm{N}(\%)$ & RR $(95 \% \mathrm{Cl})$ & $P$-value & $\mathrm{n} / \mathrm{N}(\%)$ & RR $(95 \% \mathrm{Cl})$ & $P$-value \\
\hline \multicolumn{7}{|l|}{ Type of school } \\
\hline Public & 33/417(7.91) & $4.7(1.5-21.2)$ & 0.028 & $8 / 417(2.0)$ & $0.3(0.1-1)$ & 0.043 \\
\hline Private & $3 / 216(1.4)$ & Reference & & 19/216(9.0) & Reference & \\
\hline \multicolumn{7}{|l|}{ Sex } \\
\hline Male & 16/321(5.0) & Reference & & $14 / 312(4.5)$ & Reference & \\
\hline Female & 20/312(6.41) & $1.4(0.7-2.7)$ & 0.360 & $13 / 321(4.0)$ & $1.1(0.5-2.0)$ & 0.777 \\
\hline \multicolumn{7}{|c|}{ Location of school } \\
\hline Rural & 24/291(8.25) & $1.2(0.5-2.7)$ & 0.602 & $3 / 291(1.0)$ & $0.2(0.1-2.3)$ & 0.435 \\
\hline Urban & $12 / 341(3.5)$ & Reference & & 24/342(7.0) & Reference & \\
\hline \multicolumn{7}{|c|}{ Age of pupils (years) } \\
\hline $3-5$ & $5 / 116(6.0)$ & Reference & & 2/116(1.7) & Reference & \\
\hline $6-12$ & $31 / 517(5.01)$ & $0.2(0.0-1.9)$ & 0.147 & 25/517(4.8) & $1.1(0.5-20.1)$ & 0.927 \\
\hline \multicolumn{7}{|c|}{ Fruit consumption $\geq 3$ times weekly } \\
\hline No & 24/473(3.87) & Reference & & 18/473(3.8) & Reference & \\
\hline Yes & $12 / 160(7.5)$ & $0.6(0.3-1.4)$ & 0.207 & 9/160(5.6) & $1.3(0.6-3.2)$ & 0.417 \\
\hline \multicolumn{7}{|c|}{ Eats breakfast every morning before school } \\
\hline No & 3/38(7.9) & Reference & & $1 / 38(2.6)$ & Reference & \\
\hline Yes & 33/595(5.6) & $1.4(0.4-5.3)$ & 0.599 & 26/595(4.4) & $5.6(0.5-56.5)$ & 0.147 \\
\hline \multicolumn{7}{|c|}{ Frequency of meals in a day } \\
\hline Twice daily & $3 / 10(30.0)$ & $9.4(2.0-47.8)$ & 0.007 & $1 / 6(16.7)$ & $1.0(0.8-14)$ & 0.078 \\
\hline 3 times daily & 26/466(5.6) & Reference & & $17 / 470(3.7)$ & Reference & \\
\hline 4 times daily & $7 / 157(4.5)$ & $1.0(0-2.7)$ & 0685 & 9/157(5.7) & $0.7(0.3-1.7)$ & 0.441 \\
\hline \multicolumn{7}{|l|}{ Class group } \\
\hline Kindergarten & $5 / 167(3.0)$ & $0.2(0-1.9)$ & 0.158 & 3/167(1.8) & $0.3(0.1-1.4)$ & 0.290 \\
\hline Class $1-3$ & 10/242(4.1) & Reference & & $11 / 242(4.5)$ & Reference & \\
\hline Class 4-6 & $21 / 242(9.4)$ & $2.3(1.0-5.2)$ & 0.045 & $13 / 224(5.8)$ & $1.6(0.7-3.7)$ & 0.280 \\
\hline \multicolumn{7}{|c|}{ Guardian occupation } \\
\hline Formal sector & $1 / 45(2.2)$ & $1.0(0.1-12.4)$ & 0.978 & 2/46(4.4) & $0.3(0.1-1.4)$ & 0.123 \\
\hline Petty trading & 11/239(4.6) & $1.9(0.4-9.5)$ & 0.399 & $10 / 239(4.2)$ & $0.5(0.2-1.1)$ & 0.093 \\
\hline Unemployed & 6/81(7.4) & $2.3(0.4-13.0)$ & 0.333 & $5 / 81(6.2)$ & $0.8(0.2-2.9)$ & 0.788 \\
\hline Artisan & $2 / 89(2.3)$ & Reference & & 9/89(10.1) & Reference & \\
\hline Farming & 15/178(8.4) & $2.7(0.5-13.1)$ & 0.230 & $1 / 178(0.6)$ & $0.1(0.01-1)$ & 0.049 \\
\hline \multicolumn{7}{|c|}{ Prob $>c h i^{2}=0.0000$, Pseudo $R^{2}=0.1462$} \\
\hline
\end{tabular}

Similarly, there was high proportion of underweight, stunting and thinness among pupils attending schools in rural areas compared to those attending schools in urban areas. It was observed that pupils attending schools in the rural areas were more likely to become stunted compared to those attending schools in urban areas. Moreover pupils, who had only two meals per day were likely to be underweight, stunted and thin compared to those who had at least three square meals a day.
Additionally, pupils whose parents or guardians are engaged in petty trading were less likely to be underweight, stunted and thin compared to those whose parents are employed in the formal sector (civil and public servants). Also, pupils in the upper primary were more likely to be thin compared to those in the lower primary.

The type of school attended was found to be a strong determinant of underweight and thinness among pupils. This observation is consistent with many other studies that investigated malnutrition and associated factors 
among children. For example one study conducted in Burkina Faso shows that private school children had a better nutritional status than those attending public schools, with anaemia and vitamin A deficiency significantly higher in children attending public schools $(30 \%$ vs. $45 \%$ and $6 \%$ vs. $53 \%$ respectively) [22]. They postulated that socio-economic conditions [23] of the individual children may be responsible for these differences observed as school registration fees was markedly different between the two schools: US \$ 60 in private schools compared with only US $\$ 4$ in public schools. This observation is consistent with our findings. Similarly another study conducted in India in 2014 also showed high proportion of underweight among children attending government schools compare to those attending private schools [24].

Other studies in Ghana [31] and elsewhere in Africa $[1,32]$ found that the various socio-economic status indicators such as maternal education and paternal educational level, parental income level and family assets were associated with children nutritional status. More so, the Ghana Demographic and Health Survey in 2014 [33] also showed that stunting among children was inversely correlated with education and wealth in Ghana. Perhaps the reasons for suboptimal nutrition of pupils from the poor households (pupils in public schools) could be due to the fact that poor households and individuals are not able to achieve food security or have better resources for care and for that matter, they are unable to utilize or create resource for health on a sustainable basis [29].

Conversely there was a high proportion of overweight among pupils attending private schools compared to those attending public schools. This observation is in accordance with findings of other studies. For example, a significantly higher overweight prevalence was found among pupils in private than public schools in Burkina Faso [22]. Similar findings have been observed in other developing country $[23,24]$.

Additionally, location of pupils (rural vs. urban) was found to be an important determinant of stunting as pupils in rural areas were several folds more likely to become stunted compared to those in urban areas. This finding is in agreement with the findings of the Ghana demographic and Health survey in children under-five years, which shows higher proportion of underweight among rural children compared to those in urban areas [33]. Another study in Ethiopia [34] also found high proportion of malnutrition among rural school children compared to their urban counterparts. Perhaps the poor nutritional status observed in pupils attending schools in rural communities is as a result of the usual higher prevalent rates of intestinal parasites especially among rural children compared with urban dwellers and the likelihood of inadequate food intake in the rural areas could contribute to the disparity in the nutritional status between the children in both communities [35].

The better nutritional status of pupils in urban communities in the present study is also in conformity with those of other studies among school children in Nigeria [36] and other developing countries [23]. The differences observed could also be due to differences in the socioeconomic status of their parents [37].

Moreover, there was a high proportion of overweight among pupils attending schools in urban areas compared to those in rural areas. The prevalence of overweight among pupils attending school in rural areas was smaller compared to those in urban areas. This appears to follow the same trend as adult over-nutrition in Ghana, which is higher among urban population than rural population [38]. This could be due to the modification in life style, diet, urbanization, and reduced active commuting to school, use of energy saving devices and increasing sedentary games such as computer games and television watching that creates an 'obesogenic' environment [39].

Number of meals consumed per day was also found to be independently associated with stunting, underweight and thinness. It was observed that pupils who had only two meals a day had increased odds for stunting and underweight as well as higher risk of been thin. This observation is in conformity with the findings of other studies. For example, according to the WHO, [40] when children do not take adequate number of meals recovery from infections takes longer. More so, it is found that decreased number of meals per day leads to malnutrition among children [41]. This could be due to the fact that adequate supply of foods is important for a child's growth, as it prevent diseases as well as maintains health.

Furthermore, guardian's occupation was also associated with the nutritional status of pupils as it was observed that pupils whose parents are engaged in petty trading had decreased odds for both underweight and stunting as against those whose parents are in the formal sector. Perhaps, as a result of the flexible nature of their work schedules, parents or guardians who are engaged in petty trading are able to provide adequate care in terms of providing adequate meals at the required frequency as compared to their counterparts in the formal sector.

One important limitation of this study is that it was a school based cross sectional study and for that matter the findings may not be representative of the nutritional situation of children of the same age group who are not in school, as some of the schools had school meals. Moreover children who are not in schools may have poorer background and consequently poorer nutritional status compare to those who are in school. 


\section{Conclusion}

On the whole the study revealed that both under nutrition and over nutrition are common among pupils in public and private schools but over nutrition appeared to be largely driven by improved socio-economic status and urbanization. More so, low socio-economic status and rural dwelling according to our findings could preclude optimal nutrition in children. Our findings also reinforce the most important causes of malnutrition including inadequate food consumption and poor parental care. It is important to emphasize that nutrition interventions targeting school children should aim at reducing poverty and hunger in general as these factors remain the underlying causes of malnutrition in children. Interventions implemented to address overweight and obesity should also be channeled through the schools particularly in private schools and urban areas, as children in these settings are more prone to overweight and obesity.

Besides this, in schools where meals are served it is imperative that optimal diet that contains all the nutrients required for the proper growth of children should be provided. Moreover, efforts should be made to control the spread of common childhood infections such as malaria, diarrhea and worm infestations.

\section{Abbreviations}

$A O R$, adjusted odds ratio; BAZ, body mass index for-age-z-scores; BMI, body mass index; MAZ, mid upper arm circumference for-age-z-scores; RR, risk ratio; WHO, the World Health Organization.

\section{Acknowledgement \\ The authors thank the Hohoe municipal directors of education and health for granting permission to carry out the study, and also to all school heads and class teachers in the public and private basic schools within the municipality where the study was conducted. We appreciate parents and guardians who consented for their wards to be part of the study and assisted with eliciting information from the younger pupils.}

\section{Funding}

We did not receive external funding for this research.

\section{Availability of data and materials}

We could not share our dataset as we still have interest in the data. Plans are in the pipeline to submit another research work by using this dataset; therefore, our dataset could not be shared.

\section{Competing interests}

All authors declare that they have no competing interests.

\section{Authors' contributions}

FA, PA, conceived and designed the study. FA, AA did the data analysis and interpretation. PA was involved in protocol development, data collection and entry. AA, FA wrote the first draft of the manuscript. PA contributed to writing the manuscript. All authors read and approved the final manuscript.

\section{Ethics approval and consent to participate}

The study protocol was reviewed and approved by the Ghana Health Service Ethics Review Committee (GHS-ERC: 15/04/15. Permission was sought from Municipal Health and Education Directorates of the Hohoe municipality. Informed consent was obtained from parents and guardians of the school children while the later provided assent to participate in the study.

\section{Author details}

'Department of Family and Community Health, School of Public Health, University of Health and Allied Sciences, Ho, Ghana. ${ }^{2}$ Institute of Public Health, University of Heidelberg, Heidelberg, Germany. ${ }^{3}$ Community Nutrition Department, School of Allied Health Sciences, University for Development Studies, P.Box TL 1883, Tamale, Ghana.

Received: 14 February 2016 Accepted: 2 June 2016

Published online: 06 June 2016

\section{References}

1. Abubakar A, Uriyo J, Msuya SE, Swai M, Stray-Pedersen B. Prevalence and risk factors for poor nutritional status among children in the Kilimanjaro region of Tanzania. Int J Environ Res Public Health. 2012;9(10):3506-18.

2. Srivastava A, Mahmood SE, Srivastava PM, Shrotriya VP, Kumar B. Nutritional status of school-age children - A scenario of urban slums in India. Arch Public Health. 2012;70(1):8.

3. Wisniewski SLW. Child Nutrition, Health Problems, and School Achievement in Sri Lanka. World Dev. 2010;38(3):315-32.

4. Muller $\mathrm{O}$, Krawinkel M. Malnutrition and health in developing countries. CMAJ. 2005;173(3):279-86.

5. Prentice AM. The emerging epidemic of obesity in developing countries. Int J Epidemiol. 2006:35(1):93-9.

6. Cattaneo A, Monasta L, Stamatakis E, Lioret S, Castetbon K, Frenken F, Manios Y, Moschonis G, Savva S, Zaborskis A et al. Overweight and obesity in infants and pre-school children in the European Union: a review of existing data. Obes Rev. 2010;11(5):389-98.

7. Bertoncello C, Cazzaro R, Ferraresso A, Mazzer R, Moretti G. Prevalence of overweight and obesity among school-aged children in urban, rural and mountain areas of the Veneto Region, Italy. Public Health Nutr. 2008;1 1(9): $887-90$

8. FAO. The double burden of malnutrition. Case studies from six developing countries. FAO Food Nutr Pap. 2006:84:1-334.

9. Thiam ISK, Lwanga D. Diet related chronic disease in the West Africa Region. in Diet-related chronic diseases and the double burden of malnutrition in West Africa. In: SCN News, vol. 33. Geneva: SCN; 2006. p. 6-10.

10. Mendez MA, Monteiro CA, Popkin BM. Overweight exceeds underweight among women in most developing countries. Am J Clin Nutr. 2005;81(3): 714-21.

11. Popkin BM. Using research on the obesity pandemic as a guide to a unified vision of nutrition. Public Health Nutr. 2007:8(6a):724-729.

12. Zhang YX, Zhao JS, Chu ZH. Prevalence of overweight and obesity among children and adolescents is associated with urbanization in Shandong, China. Int J Cardiol. 2014;176(3):1212-3.

13. Delisle HF. Poverty: the double burden of malnutrition in mothers and the intergenerational impact. Ann N Y Acad Sci. 2008;1136:172-84.

14. Fernald LC, Neufeld LM. Overweight with concurrent stunting in very young children from rural Mexico: prevalence and associated factors. Eur J Clin Nutr. 2007;61(5):623-32.

15. Alkali YSAJ, Sabin M, Zacharin M. Socio-economic status, lifestyle and childhood obesity in Gombe. Niger J Paediatr. 2015;42:107-10.

16. Adegoke SA, Olowu WA, Adeodu OO, Elusiyan JB, Dedeke IO. Prevalence of overweight and obesity among children in lle-ife, south-western Nigeria. West Afr J Med. 2009;28(4):216-21.

17. Lobstein T, Baur L, Uauy R. Obesity in children and young people: a crisis in public health. Obesity reviews : an official journal of the International Association for the Study of Obesity. 2004;5 Suppl 1:4-104.

18. Ojiako IA, Manyong VM, Ikpi AE. Determinants of nutritional status of preschool children from rural household in Kaduna and Kano States, Nigeria. Pak J Nutr. 2009;8:1497-505.

19. Mikiko Nishimura TY. School Choice between Public and Private Primary Schools under the Free Primary Education Policy in Rural Kenya. In. Kenya: GRIPS Policy Information Center; 2008.

20. Peter Glick DE. The Demand for Primary Schooling in Madagascar: Price, Quality, and the Choice Between Public and Private Providers. J Dev Econ. 2006;76(1):118-45.

21. Gaddah M, Munro A, Quartey P. Education subsidy and school enrollments in rural Ghana. Int J Educ Dev. 2016:46:143-52.

22. Dabone C, Delisle HF, Receveur O. Poor nutritional status of schoolchildren in urban and peri-urban areas of Ouagadougou (Burkina Faso). Nutr J. 2011;10:34. 
23. Groeneveld IF, Solomons NW, Doak CM. Nutritional status of urban schoolchildren of high and low socioeconomic status in Quetzaltenango, Guatemala. Rev Panam Salud Publica. 2007;22(3):169-77.

24. Kavitha HS, Kulkarni P, Ashok NC. A comparative study of nutritional status between government and private primary school children of Mysore city. Int J Health Allied Sci. 2014;3(3):164.

25. United Nations Children's Fund, World Health Organization, The World Bank. UNICEFWHO- World Bank Joint Child Malnutrition Estimates. UNICEF, New York; WHO, Geneva; The World Bank, Washington, DC, 2012.

26. UNICEF. The State of the World's Children 2015: Reimagine the Future: Innovation for Every Child. In: New York, USA: United Nations Children's Fund; 2015: 116

27. Ghana Statistical Service: Ghana Demographic and Health Survey Key Indicators. In: Accra, Ghana: Ghana Statistical Service, Ghana Health Service, Ghana, The DHS Program, ICF International, Rockville, Maryland, USA: 2015.

28. Ghana Statistical Service. Ghana Demographic and Health Survey 2008. In: Accra, Ghana: (Ghana Health Service; Ghana Statistical Services: Ghana Health Service Accra, Ghana and ICF Macro Calverton, Maryland, USA; 2008.

29. Smith LC, Haddad L. Explaining Child Malnutrition in Developing Countries. A Cross-Country Analysis. Washington DC: Library of Congress Catalogingin-Publication Data; 2002.

30. Ghana Statistical Service. Population and Housing Census Final Results. In: Accra, Ghana: Ghana Statistical Service; 2012.

31. Owusu WB, Lartey A, de Onis M, Onyango AW, Frongillo EA. Factors associated with unconstrained growth among affluent Ghanaian children. Acta Paediatr. 2004:93(8):1115-9.

32. Engebretsen IM, Tylleskar T, Wamani H, Karamagi C, Tumwine JK. Determinants of infant growth in Eastern Uganda: a community-based cross-sectional study. BMC Public Health. 2008;8:418.

33. Ghana Statistical Service/Ghana Health Service. Ghana Demographic and Helath Survey, Key indicators. In: Accra, Ghana: Ghana Statistical Service/ Ghana Health Service/ DHS Program ICF International; 2014: 1-45.

34. Herrador Z, Sordo L, Gadisa E, Moreno J, Nieto J, Benito A, Aseffa A Canavate C, Custodio E. Cross-sectional study of malnutrition and associated factors among school aged children in rural and urban settings of Fogera and Libo Kemkem districts, Ethiopia. PLoS One. 2014;9(9):e105880.

35. Ogbonna C, Okolo SN, Okonji MC. Intestinal wormsand nutritional status of under-fives in Jos, Nigeria: any relationship? Nig J Clin Pract. 2004;7:79-81.

36. Oninla SO, Owa JA, Onayade AA, Taiwo O. Comparative Study of Nutritional Status of Urban and Rural Nigerian School Children. J Trop Pediatr. 2007; 53(1):39-43.

37. Ghana Statistical Service. Population and housing census. In: Accra, Ghana: Ghana statistical service; 2010.

38. Konan ER. Epidemiology of adiposity in Ghanaian women of childbearing age: a comparative study between urban and rural place of residence. Atlanta, USA: School of Public Health Georgia State University; 2010

39. Popkin BM. Using research on the obesity pandemic as a guide to a unified vision of nutrition. Public Health Nutr. 2005:8:724-9.

40. WHO. Food and Nutrition needs in Emergencies. In: Geneva: WHO; 2002

41. Jukes M. The long-term impact of preschool health and nutrition on education. Food Nutr Bull. 2005;26(2 Suppl 2):S193-201.

\section{Submit your next manuscript to BioMed Central and we will help you at every step:}

- We accept pre-submission inquiries

- Our selector tool helps you to find the most relevant journal

- We provide round the clock customer support

- Convenient online submission

- Thorough peer review

- Inclusion in PubMed and all major indexing services

- Maximum visibility for your research

Submit your manuscript at www.biomedcentral.com/submit

) Biomed Central 